\title{
The development of cluster technology of educational programs of culture and art
}

\author{
Nataliya Malshina ${ }^{1, *}$, Alexander Demchenko ${ }^{1}$, and Anastasia Filonenko ${ }^{2}$ \\ ${ }^{1}$ Saratov State Conservatoire named after L. V. Sobinov, 410012 prospect named after S. M. Kirov, \\ h. 1, Saratov, Russia \\ ${ }^{2}$ Saratov State University named after N. G. Chernyshevsky, 410012, Astrakhanskaya street, 83, \\ Saratov, Russia
}

\begin{abstract}
The use of natural science research methods in the form of cluster analysis in the field of humanities on the example of the education system of culture and art gives an innovative direction to the development of the entire field of culture. The main significance of this development has an applied character, what contributes to the forming of the innovative potential of the territory and the attractiveness of the region. As a result of the proposed research, a method of cluster analysis of the education system of culture and art is developed, an algorithm for implementing the cognitive-hermeneutical methodology of teaching and approving the principles of self-development of students, as well as the realization of the role of globalization processes are proposed. The method of factor analysis in the application for the cultural sphere was tested. Recommendations, key indicators and author's methods of development of the higher education system of culture and art are formed, taking into account the specifics of music education.
\end{abstract}

\section{Introduction}

The most advanced factors of modern art education reform are the development of cluster technology of educational programs, the realization of the role of globalization processes, the introduction of cognitive-hermeneutical teaching methodology, and full adoption of the principles of students' self-development. Before considering these four factors, which will be the subject of the next article, it is necessary to focus on the initial basic component of art education, which is the periodization and regularities of the artistic and historical process.

\subsection{Formatting the title, authors and affiliations}

The purpose of this article is to develop theoretical bases, as well as practical methods for the development of innovative education of culture and art - cluster technology of educational programs of culture and art. The objectives of this article are the analysis of the specificity of functioning and learning in higher education of culture and art, the application

* Corresponding author: malsnataliya@yandex.ru 
of the cluster analysis methodology of the system of higher education of culture and art and the identification of cluster formation factors, the development of cluster technologies in the educational programs of culture and art, the realization of the role of globalization in the higher education system of culture and art, the introduction of cognitive-hermeneutic methodology of artistic education, full adoption of the principles of students' selfdevelopment, formation of recommendations, key indicators and author's methods for the development of the higher education system based on the specifics of artistic education, forecasting the development of the cultural industry in general and of the higher education system in particular. To solve successfully the general goal of the study, firstly it is supposed to outline the general coordinates of the retrospective of world artistic culture and to identify certain patterns of its evolution that allow predicting its subsequent development.

The diversity of regional cultural differences makes it possible to build regional cultural clusters - a set of cultures with similar properties. The development and promotion of cultural and educational clusters is an innovative approach to the adaptation and development of large and small constituent entities of the Russian Federation [1], a stage in the development of the territory with the help of new technologies in the field of culture.

The creation of cultural and educational clusters contributes to the growth of activity, the improvement of innovation potential of a region, development of social, economic, information and integration systems, which, in turn, will give impetus to more intensive growth of enterprises in the field of culture, attracting investment and economic growth of territories.

\subsection{Methods of research}

Methodological basis of research is fundamental scientific works of Russian and foreign scientists on the theory and practice of functioning of the higher education system in the sphere of culture and art, as well as the works on theoretical and methodological basics of the implementation of innovative processes in the education system, the problems of clustering and improving the efficiency of the cultural industry.

The research uses general scientific methods of cognition: analysis, induction and deduction, abstraction, systematization, structuring, classification. The solution of the set tasks is based on the application of the cognitive-hermeneutical method; institutional, comparative and system analysis; factor and cluster analysis, and organizational modelling.

\section{Theoretical bases}

Turning to the consideration of the factors of modern art education reform, the following ones are the most advanced:

- the development of cluster technology of educational programs,

- the realization of the role of globalization processes,

- the introduction of cognitive-hermeneutical teaching methodology,

- the full adoption of the principles of students' self-development.

The basic point of this study is to define objective laws of cultural and historical process: the effect of such factors as "triplicity" of each era (it consists of three epochs) and "fivefold character" of each epoch (it consists of five periods), as well as the integral role of interaction and alternate prioritizing one of the two defining types of mentality and, accordingly, methods of artistic creation - either romanticism or realism.

Looking into the near future, we can assume that in the 2020-2040s, a new transition period is coming, when the outgoing Modern will be combined with the initial phase of the next, emerging epoch, the second one in the era of Contemporary times, perhaps, its name 
will be Inform. The preference for this name is determined due to the fact that the rapidly growing importance of all kinds of digital, virtual and cluster technologies is already evident. This is clearly observed in our days, and it has become more and more insistent to talk about it since 2020 .

In accordance with the logic of previous calculations, we can expect that the duration of the periods of the Inform epoch will be about a quarter of a century, and the entire epoch will take less than half a century, that is, it will last until the middle of the 21 st century. «Then there is a reason to expect that the final period of Modern should prepare the ground for the next epoch. And if this next epoch, which probably has already begun (the period of the 2020s-2040s noted above), really turns out to be more or less organic, then there is hope that, despite all the dark prophecies, humanity and its art will "last" at least until the middle of the 22nd century» [2]. But the next "darkening" can lead to the last "shadow", that is, to the final "end of the world"...

Everything recorded in the works of artistic creativity of the historical period, with varying degrees of approximation and adequacy reflects what is happening in reality of the corresponding time. Consequently, «what has been said about the regularities of artistic and historical evolution can be applied with sufficient grounds to a general historical process» [2]. Thus, the conclusions addressed to the world of culture and art can be considered applicable to the phenomena of life in general. And the conclusions «made above in relation to cultural and historical evolution can be successfully extended to any sphere of the ontology, including being used to predict the near and distant prospects of the existence of the Earth's civilization» [3].

Internationally, in studying cluster analysis of cultures, several approaches to the classification of countries (cultures) with similar properties have been identified [4]. G. Hofstede's research in this area of knowledge is generally recognized and can be considered as the basic research for this problem [5]. His factor analysis showed the presence of cultural indices: the "power distance" index (PD) reflects the degree of power inequality in the organization (centralization of power and autocratic leadership), avoidance of uncertainty, assertiveness - focus on achieving results at any cost, strategic thinking (short-term or long-term orientation to the future) and individualism.

Thus, by synthesizing previous studies, the following countries (clusters) were identified [6]:

- Scandinavian cluster: Finland, Norway, Sweden, Denmark;

- German cluster: Germany, Austria, Switzerland;

- English-speaking cluster: the USA, the UK, Australia, South Africa, Canada, New Zealand, Ireland;

- Romanesque cluster: France, Italy, Spain, Portugal, Belgium;

- Latin American cluster: Argentina, Chile, Colombia, Peru, Mexico, Venezuela;

- the Far East cluster: Thailand, Indonesia, Taiwan, the Philippines, Singapore, Hong Kong, Vietnam;

- Arab cluster: Bahrain, Kuwait, the UAE, Oman, Saudi Arabia;

- the Middle East cluster: Turkey, Greece, Iran.

The following classification factors were selected: the degree of satisfaction with working conditions; division of labour roles; interpersonal labour relations; business methods.

Some of the country classifications considered by the authors (Brazil, Japan, India, Israel) were not included in any cluster. However, for Russian practice, this classification and the selected classification factors cannot be transferred without taking into account regional and national cultural specifics.

In addition, there are five dimensions of classification and differentiation of countries into clusters [7] - English (the USA, Great Britain); Asian (Japan, China, Indonesia, Hong 
Kong, Singapore); Latin American (Argentina, Mexico, Venezuela, Brazil); LatinEuropean (France, Belgium, Spain, Italy); German (Austria, Germany, Switzerland, Czechoslovakia). The following classification factors were selected: individualism / communitarianism; special relations / diffuse relations; universalism / specialization; neutral cultures / emotional; culture of achievements / culture of belonging. The disadvantages of this classification may include blurring and similarity of the profiles of some clusters.

It is possible for cultures to move from one cluster to another over time, as indicators for selected factors change, and the factors themselves lose their relevance [8].

Therefore, it is necessary to improve the methodology of comparative studies of cultures and take into account the Russian reality when choosing classification factors.

The idea of developing a cluster technology for educational programs of culture and art is based on the fact that the teaching of most disciplines in art institutes is completely disjointed. It seems that it would be much more effective to study purposefully the cycle of special subjects in their close connection with the development of the entire range of humanitarian knowledge traditionally presented in the process of higher education.

In this case, we are talking about a multidisciplinary approach, which most urgently requires the use of the cluster principle in the educational process. The term in this case implies the integration of resources of various disciplines taught in the art institute for the comprehensive development of the presented material in its diversity and integrity.

\section{Discussion}

Suggestions for solving the problem set in this study are considered on the example of higher music education. In order to overcome the fragmentation of the study of social sciences and musical-theoretical subjects, a connecting point is needed, which is the basis of the courses. This can be the principle of historicism as the development of the entire cycle in parallel, synchronous deployment of the material - from the origins to the present, in the movement from epoch to epoch. This will allow the student to get a complete, comprehensive view of the integral and consistent development of the musical-historical process in its relations with general historical and general artistic processes.

It is relatively easy to implement such transformations in the presentation of musical and historical disciplines, which requires overcoming the tradition of separate presentation of the history of Russian and foreign music, as well as "dissolving" the recitation of modern music in the course of the history of music of the 20th century. Strict profiling of the musical-theoretical disciplines (solfeggio, harmony, polyphony, analysis of musical works, etc.) complicates its transformation on a historical basis. It is necessary to abandon the categorical division of this cycle into independent disciplines and return to the original, generic concept of music theory. Only on this basis is it possible to cover the musical and theoretical problems of a particular era in its entirety with a comprehensive analysis of all the necessary components - from melos and rhythm to texture and orchestration, from harmony and polyphony to drama and architectonics.

This way leads to a holistic study of the musical style, which includes various instruments and techniques - there is nothing fundamentally new here, since a thorough consideration of the musical language was once practiced in conservatories in a course called composition. The distribution of study time on subjects is based on the specialization of students: for example, for composers, one of the most important focuses is on instrumentation and reading scores, for vocalists - on solfeggio. Thus, the connection into a single complex of musical-historical disciplines (overcoming barriers of separate presentation of Russian and foreign music history) and disciplines of music theory cycle (solfeggio, harmony, polyphony, analysis of musical works, etc.). One should consider also 
the issue of the inclusion in the overall system some of the more special items such as musical culture of the world, opera dramaturgy, musical pedagogy and psychology, history, performing arts, piano styles, etc.

Simultaneous studying the historical epoch in various aspects (humanitarian, artistic, musical-historical and musical-theoretical) will undoubtedly increase the effectiveness of training and give students an orientation in the processes of evolution of humankind, a holistic idea of them. The introduction of a systemic approach could provide a better learning efficiency than its current state. Concentration would make it possible to achieve a qualitative increase, but there would be an opportunity to avoid any kind of duplication. This project is aimed at the final result for which the conservatory exists - the upbringing of a highly skilled musician. To achieve this goal, it makes sense to combine the efforts of teacher-musicians and teacher-humanists, to move away from established canons that retard a breakthrough to a qualitatively new level of the educational process.

The realization of the role of globalization processes was closely linked to the set of issues relating to the use of cluster technology in artistic education. There are many reasons to discuss actively these processes in the current world - it is enough to look at what is happening in the field of information technology, world communications, socio-political and economic contacts, etc. Unfortunately, the integration dominant does not actively declare itself in the field of art education (both special and in the entire system of university training), as well as in the musical education in particular.

The most effective way to organize the educational process is to provide educational material by epoch. In this case, the student reconstructs for himself a complete panorama of the gradual evolution of humanity, which appears in the prism of developing artistic matter. By achieving an organic integration of national and international, Russian and foreign components, we could contribute to the formation of a well-educated humanist who quite freely interprets the world culture.

Therefore, the main idea is to ensure that the world artistic culture is presented exactly as a world culture. That is, in a single stream, with overcoming national borders and with a holistic coverage of all types of art. It also includes bypassing the usual categorization by individual styles and individual genres. Among other things, this panoramic technique of the world history of art allows students to select the most valuable and significant items in it and thus to immerse in the world of the highest artistry.

The total development of the art created by artists in the form of a systematic retrospective of the cultural process can significantly enrich the inner world of a person; bring him or her closer to the ideal of a fully developed personality. The undoubted relevance of the approach discussed above is also determined by the desire to stimulate the desire for knowledge and awareness of general trends and patterns of development of the Earth's civilization through a universal-integrating vision of the world cultural process. In other words, it allows us to develop the individual's ability to think and feel globally, as required by the prospect of human progress at the turn of the third Millennium, through the formation of a holistic, comprehensive view of the world culture.

Turning to the cognitive-hermeneutical methodology of teaching in the educational sphere, let us start with the necessary explanations. The cognitive approach does not involve passive perception of artefacts and memorizing information about them, but the process of cognition, the desire to penetrate the essence of the studied phenomena. In other words, it is planned to rely on the principle of conscious attitude to artistic material, its active perception.

Hermeneutics (from the Greek "to explain, interpret") aims to understand and interpret artefacts, to identify their content. This implies a kind of decoding of artistic texts, interpretation of the ideological and figurative concepts they imply, based on the idea that 
they undoubtedly contain a certain spiritual substance, and the true phenomena of art contain deep meanings of being.

Cognitive science and hermeneutics as mechanisms of cognition and understanding are complementary concepts that together determine the focus on active, conscious perception of artefacts and the desire to feel them (including through spiritual experience), to understand their essence and meaning. At the same time, the ontological effect is selfevident: a work of art is regarded as a special type of implementation and generalization of human experience and through knowledge/understanding of art, knowledge/understanding of the world and the human is realized.

The most productive instrument for implementing the cognitive-hermeneutical approach is the conceptual method of artistic and historical analysis. In this case, we are talking about the analysis of a music work.

In art studies and pedagogy, various methods of artistic and historical analysis are used - from sequential-descriptive to problem generalizing. A common drawback in this case is that the consideration of works sometimes results in the sum of various kinds of observations, aspects, and points of view that are not connected by the logic of a single connecting link. The conceptual basis of the work can serve most effectively as such a link.

Another important component of the cognitive hermeneutical methodology is that students are not only the object of the teacher's learning activities, but also active participants in the learning process. In this regard, the full approval of the principles of selfdevelopment of students is of particular importance.

The current situation of Russian life publicly sounds the alarm about the sharply expressed "decline in morals", which began in perestroika times and continues to this day. This is largely true of the new generations of Russian intellectuals who have entered the life arena in recent decades. One of the possible ways to overcome its crisis state is seen to enhance the impact of a discipline called "world culture" (hereinafter - the WC) on the consciousness of the young. First, it makes sense to clarify the concept of intelligence.

This spiritualizing principle is especially concentrated in the artistic memory of humankind. Moreover, the most important resource for self-preservation and self-survival of the intelligence is to join this priceless storehouse as much as possible. The ultimate task of those who are intended to start and develop such communion is to bring it to the level of self-development of an individual.

Analysing the state of the educational process, one can see one of its most important disadvantages in the fact that both at school and at the university, the acquiring of knowledge is focused on reproduction, but not on the development of the creative potential of students [9]. This is the challenge of modern pedagogical science: to give students the rise in their development and provide them with the perspective of further self-education.

It is the hope of the authors that the Russian educational system will be able to accept such an initiative and creative approach in order to adapt to new historical conditions, to bring up intelligent people. This hope is based on the fact that the terms "intellectual" and "intelligentsia" originated in Russia in the second half of the nineteenth century, and then passed to other languages and countries.

\section{Conclusions}

To sum up, let us start with the fact that all of the above was addressed to various types of special art education, which implies training in various artistic professions. As for general art education, which has educational goals, the ideas presented can be extended to it in the most General way. For example, it is preferable to avoid dividing the world heritage into separate national streams, to give preference to the combined study of various types of art as a whole, to focus on the semantic essence of artefacts, etc. 
Returning to special art education, we emphasize the obvious: the proposed new methodological approaches and ways to improve the educational process are radically transformative. Speaking about this, it should be mindful that higher art education has a long tradition and plenty of artistic experience. Unfortunately, this experience and the traditions often delay improvement and are the obstacle in the introduction of new technologies into the educational process.

The difficulties and hindrances in the way of radical reform of art education have already been repeatedly mentioned above. Based on this reality, they can be overcome not "totally", but by the method of gradual introduction of individual components of the planned modernization of art education.

In any case, it is important to understand the current inertia and established conservatism. The challenges of our time prompt us to reflect on the prospects of education in the sphere of culture and art, and in the context of increasing globalization; we must strive for "world standards". Moreover, we must think that the "universal responsiveness" characteristic of the Russian person (by F. Dostoevsky) will contribute to the successful implementation of innovative programs in this direction.

The creation of a cultural and educational cluster can be regarded as a mechanism for supporting the art and culture of a particular subject. Taking into account the specific cultural, social and economic potential of a particular region, unique innovative conditions are created for the development of creative ideas, creative economy, adaptation of large and small cities to modern socio-economic conditions, and the involvement of representatives of creative professions.

The Saratov region is known as a multicultural region that combines both ancient cultures and modern cultural communities. It attracts many tourists because it is located at the intersection of the trade routes of the east and west of Russia. Therefore, it is especially significant to take into account national characteristics and cultural diversity for strategic planning of the economic development of the region. The issue of cultural identity is particularly relevant for multicultural regions, where inter-ethnic interaction is based on tolerance in relations with each other. The problem of cultural interaction and the characteristics of each cultural group in the region should be considered taking into account a whole range of criteria: social status, ideology and culture, spiritual and moral potential, ethno-psychological stereotypes, and the language sphere. The identified cultural groups, which include communities with similar cultural values, have an impact on entering previously unused market segments of the Saratov region, and provide economic opportunities to meet the needs of culture.

The formation of a cultural cluster in the Saratov region can be considered as an innovative form of economic development in the region, which allows the introduction of natural science research methods in the humanities.

\section{Acknowledgements}

The reported study was supported by Russian Foundation for Basic Research, project "Development of organizational, economic and financial mechanisms of support and strategic development of the cultural industry in the regions of Russia” № 19-010$01004 / 20$.

\section{References:}

1. N. A. Malshina, A.N. Bryntsev, Journal of Advanced Research in Law and Economics, 6, 1825 (2017). 
2. A. I. Demchenko, Stravinsky's Ballet "The rite of Spring". The experience of conceptual analysis (2019).

3. A. I. Demchenko, Picture of the world in the musical art of Russia in the early twentieth century (2018).

4. N. A. Malshina, A. A. Filonenko, Proceedings of the 4th International Conference on Contemporary Education, Social Sciences and Humanities (ICCESSH 2019), https://www.atlantis-press.com/

5. G. Hofstede, Colture's Consequences. International Differences in Work Related Values (1980)

6. Oded Shenkar \& Simcha Ronen, Journal of Applied Behavioral Science, 23 (2), 263. (1987)

7. F. Trompenaars, $\mathrm{CH}$. Hampden-Turner, National and cultural differences in the context of global business (2004)

8. Fred. Luthans, M. Hodgetts. International Management (1991)

9. V. Andreev, T. V. Sibgatullina, Education and self-development, 4, 3(2010) 